\title{
Reuse of Ferric Sludge by Ferrous Sulfide in the Fenton Process for Nonylphenol Ethoxylates Wastewater Treatment
}

\author{
Ruoyu Zhou, Wenqi Zhang* \\ College of Chemistry and Chemical Engineering, Shanghai University of Engineering Science, Shanghai, China \\ Email: ${ }^{*}$ zhangwenqi_hit@163.com
}

How to cite this paper: Zhou, R.Y. and Zhang, W.Q. (2017) Reuse of Ferric Sludge by Ferrous Sulfide in the Fenton Process for Nonylphenol Ethoxylates Wastewater Treatment. Computational Water, Energy, and Environmental Engineering, 6, 89-96. http://dx.doi.org/10.4236/cweee.2017.61007

Received: December 12, 2016

Accepted: January 3, 2017

Published: January 6, 2017

Copyright $\odot 2017$ by authors and Scientific Research Publishing Inc. This work is licensed under the Creative Commons Attribution International License (CC BY 4.0).

http://creativecommons.org/licenses/by/4.0/

\begin{abstract}
In this paper, Fenton process was determined to be an effective technique to treat the refractory nonylphenol ethoxylates (NPEOs) wastewater. The chemical oxygen demand (COD) removal efficiencies above $89 \%$ were obtained when the initial COD concentration was $12,000 \mathrm{mg} / \mathrm{L}$. However, a large amount of ferric sludge (SS $=8.724$ $\mathrm{g} / \mathrm{L}$ ) would be produced after the Fenton oxidation of the wastewater and must be disposed appropriately. A novel process for Fenton sludge reused by low-cost ferrous sulfide (FeS) was also investigated. Experimental results show that the Fenton sludge could be reduced to produce a certain amount of $\mathrm{Fe}^{2+}$ in the acidic mixed liquor by FeS. This mixed liquor from Fenton sludge could be used as the new catalyst in the Fenton process and was also highly effective for the NPEOs wastewater treatment. The residual FeS from the mixed liquor could be used for the next batch of the reaction.
\end{abstract}

\section{Keywords}

Fenton Process, Iron-Containing Sludge, Ferrous Sulfide, Sludge Reused, Nonylphenol Ethoxylates

\section{Introduction}

The Fenton process has been extensively studied and successfully used for the treatment of various industrial wastewaters. For example, the Fenton process can be used to treat highly loaded, refractory and toxic wastewaters which cannot be biologically treated [1] [2] [3]. However, despite its simplicity, the main weakness of the Fenton process is the formation of sludge during neutralization after Fenton oxidation. The yield of Fenton sludge is dependent upon the ratio and volume of the added reagents. Due to the residual of toxic organics or heavy metals in it, sludge from the Fenton process treating recalcitrant industrial wastewater is often disposed as hazardous solid 
waste, which leads to high sludge disposal cost and the risk of secondary pollution. Therefore, Fenton sludge is the main obstacle preventing full scale application of the Fenton process in the field of industrial wastewater treatment [4].

To minimize the above-mentioned sludge formation, two approaches have been investigated: development of heterogeneous catalysts and the reuse of the iron-containing sludge.

Various heterogeneous catalysts have been developed, such as natural minerals [5], iron-containing clays [6], iron immobilized on solid support [7] and zero-valent [8] [9]. Heterogeneous catalysts are superior to the traditional homogeneous catalyst, due to the easy separation of the catalysts from the treated wastewater by sedimentation or an external magnetic field. Therefore, generation of Fenton sludge in a heterogeneous Fenton system can be reduced to some extent. However, the catalytic activity is usually deteriorated after repetitive use due to the leaching of active iron or the decay of active catalytic sites, notably in acidic condition [10].

During the Fenton treatment of wastewater, the oxidation and coagulation of ferric hydroxy complexes both contribute to the removal of the organic compounds. Therefore, the complete elimination of the coagulation step may be undesirable when a high overall process efficacy is desired. Recently, reuse of Fenton sludge has been drawing increasing interest from researchers. The reuse of iron-containing sludge as an iron source for the synthesis of a new Fenton catalyst has been reported [11]. And the sludge can also perform as Fenton catalyst after chemical regeneration with reducing agent such as hydroxylamine hydrochloride [12]. Juri et al. [13] suggested the reuse of ferric sludge without any regeneration as an iron source in the Fenton-based process displayed as a feasible solution to minimize the production of hazardous sludge waste and reduce the overall cost of the treatment process.

Ferrous sulfide $(\mathrm{FeS})$, the main component of pyrrhotite, is a kind of common iron minerals in the soil environment. In strongly acidic solution, $\mathrm{FeS}$ may dissolve into $\mathrm{Fe}^{2+}$ and sulfide $\left(\mathrm{S}^{2-}\right.$ ) (Equation (1)), and $\mathrm{S}^{2-}$ tends to transform into $\mathrm{HS}^{-}$and $\mathrm{H}_{2} \mathrm{~S}$ in acidic solution (Equations (2) and (3)). $\mathrm{H}_{2} \mathrm{~S}$ may reduce $\mathrm{Fe}^{3+}$ to $\mathrm{Fe}^{2+}$ (Equation (4)) [14]. Thereby, in theory, the iron-containing sludge can be reduced to $\mathrm{Fe}^{2+}$ by $\mathrm{FeS}$ as the catalyst for Fenton process in acidic solution.

$$
\begin{gathered}
\mathrm{FeS} \rightarrow \mathrm{Fe}^{2+}+\mathrm{S}^{2-} \\
\mathrm{S}^{2-}+\mathrm{H}^{+} \rightarrow \mathrm{HS}^{-} \\
\mathrm{HS}^{-}+\mathrm{H}^{+} \rightarrow \mathrm{H}_{2} \mathrm{~S} \\
2 \mathrm{Fe}^{3+}+\mathrm{H}_{2} \mathrm{~S} \rightarrow 2 \mathrm{Fe}^{2+}+\mathrm{S} \downarrow+2 \mathrm{H}^{+}
\end{gathered}
$$

Nonylphenol ethoxylates (NPEOs) are non-ionic surfactants that have been confirmed endocrine disruptors. They are not completely biodegradable under normal environmental conditions and would product of a large amount of foam to disturb the normal running in aeration [15] [16]. Therefore, the NPEOs wastewater needs to be disposed by other technologies such as Fenton oxidation.

In this work, a new reuse method for Fenton sludge by FeS was investigated. At first, the reactions of classic Fenton's reagent with high concentration NPEOs wastewater 
had been evaluated. Then the Fenton sludge was reduced to produce a new catalyst for Fenton process in NPEOs wastewater treatment.

\section{Experimental}

\subsection{Chemicals}

The NPEOs wastewater was obtained from a chemical enterprise in China. It is a refractory wastewater with high chemical oxygen demand (COD) $(12,000 \pm 500 \mathrm{mg} / \mathrm{L})$ and its $\mathrm{pH}$ was about 6.5. All chemicals were purchased from Sinopharm Chemical Reagent Co., Ltd (China).

\subsection{Characterization of Fenton Sludge}

The iron-containing sludge derived from the Fenton process was characterized as follows. The water content and total solid content of the iron-containing sludge was $89 \%$ and $11 \%$, respectively. The total suspended solids (TSS) was found to be $8.724 \mathrm{~g} / \mathrm{L}$, and the volatile suspended solids (VSS) was found to be $6.732 \mathrm{~g} / \mathrm{L}$, indicating the presence of abundant organics in the sludge. The total iron content of the sludge was as high as $1.4 \mathrm{~g} / \mathrm{L} \pm 0.2 \mathrm{~g} / \mathrm{L}$.

\subsection{Analytical Methods}

The COD of Fenton sludge and effluent were measured by the standard potassium dichromate method. The total iron content of the Fenton sludge and total iron leaching were determined by the phenanthroline method according to Standard Methods.

\subsection{Experimental Procedure}

The Fenton process was started when the required $\mathrm{FeSO}_{4}$ dosage was added into the beaker containing $100 \mathrm{~mL}$ NPEOs wastewater. Meanwhile, the intermixture was stirred by a magnetic stirrer with a desired stirring speed. In addition, the initial $\mathrm{pH}$ of NPEOs was adjusted by adding diluted sulfuric acid $(1 \mathrm{~mol} / \mathrm{L})$ or sodium hydroxide solutions ( $1 \mathrm{~mol} / \mathrm{L}$ ), then quickly added quantitative $\mathrm{H}_{2} \mathrm{O}_{2}$. Finally, at the selected time stopped the reaction with $\mathrm{Na}_{2} \mathrm{~S}_{2} \mathrm{O}_{3}$, and $\mathrm{COD}$ of the effluent of each batch experiment was measured.

The dissolution of FeS in acid solution had been investigated before the iron-containing sludge reduction with FeS. The experiments started when the required FeS dosage added into the beaker containing $100 \mathrm{~mL}$ required acid aqueous solution. Meanwhile, the intermixture was stirred by magnetic stirrer with desired stirring speed. And the concentration of ferrous ion was measured after filtration by $0.45 \mu \mathrm{m}$ Syringe-driven Filter.

The procedure of reusing ferric sludge in the Fenton process for NPEOs wastewater treatment was shown in Figure 1. The NPEOs wastewater solution was raised to $\mathrm{pH}>$ 7.0 with $\mathrm{NaOH}$ after Fenton oxidation process to precipitate iron-containing sludge. The sludge was separated from the solution by decantation and was dissolved in acidic conditions followed by reduction with FeS. The mixed liquor from Fenton sludge was used as the new catalyst in the next Fenton process without any sludge discharge. The residual FeS from the mixed liquor could be used for the next batch of the reaction. 


\section{Results and Discussion}

\subsection{Fenton Process}

In order to determine the optimal conditions, orthogonal experiment and single factor experiments were analyzed. And the results were $\mathrm{H}_{2} \mathrm{O}_{2}$ dosage of $76.32 \mathrm{mmol} / \mathrm{L}$, molar ratio of $\mathrm{H}_{2} \mathrm{O}_{2} / \mathrm{Fe}^{2+}$ of $3, \mathrm{pH}$ value of 5 . Under the optimum operation conditions, the COD removal efficiency was expressed in Figure 2.

As can be seen from Figure 2, about $50 \%$ of the COD of the NPEOs wastewater was degraded in 30 minutes of the reaction. Then the COD removal increases significantly with the reaction time and stabilized at $89 \%$ in $2 \mathrm{~h}$. In this Fenton experiment, when the initial COD concentration was $12,000 \mathrm{mg} / \mathrm{L}$.

In this study, the efficiency of COD removal were still high in the initial $\mathrm{pH}$ of 5 . But the $\mathrm{pH}$ of all effluents after Fenton process was less than 3 . This showed that the $\mathrm{pH}$ of the wastewater was decreasing in the reaction process which may be due to the production of some intermediate products, such as nonylphenoxy carboxylic acids (NPEC)

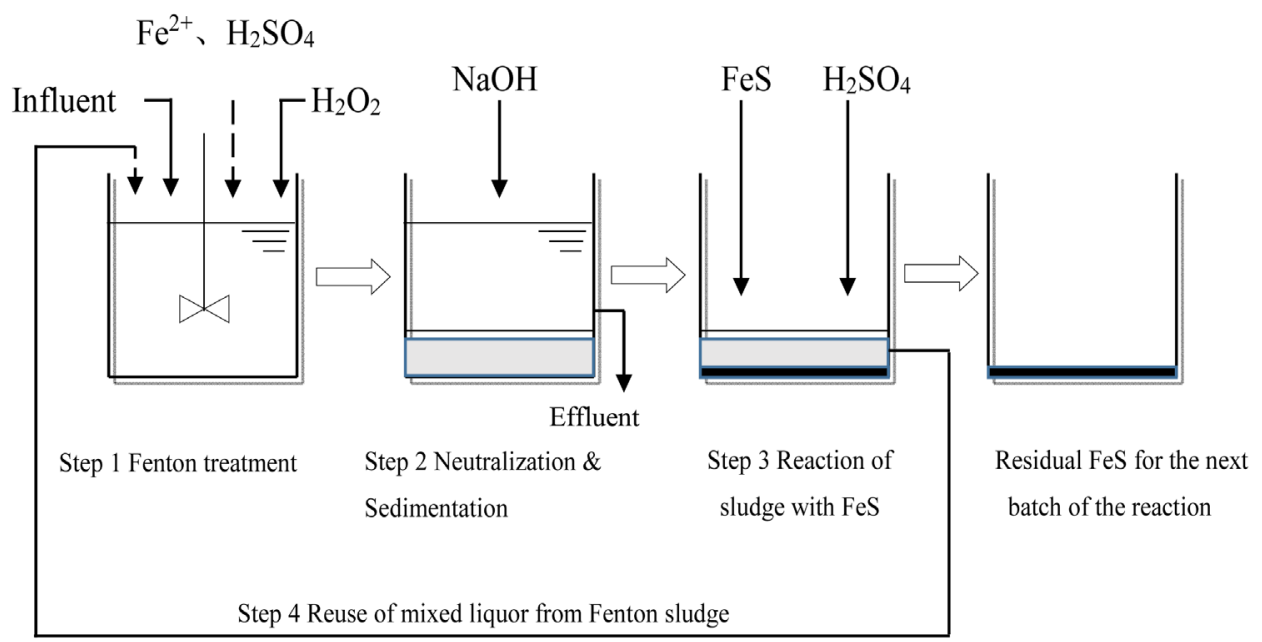

Figure 1. Schematic diagrams of Fenton process with reuse of ferric sludge.

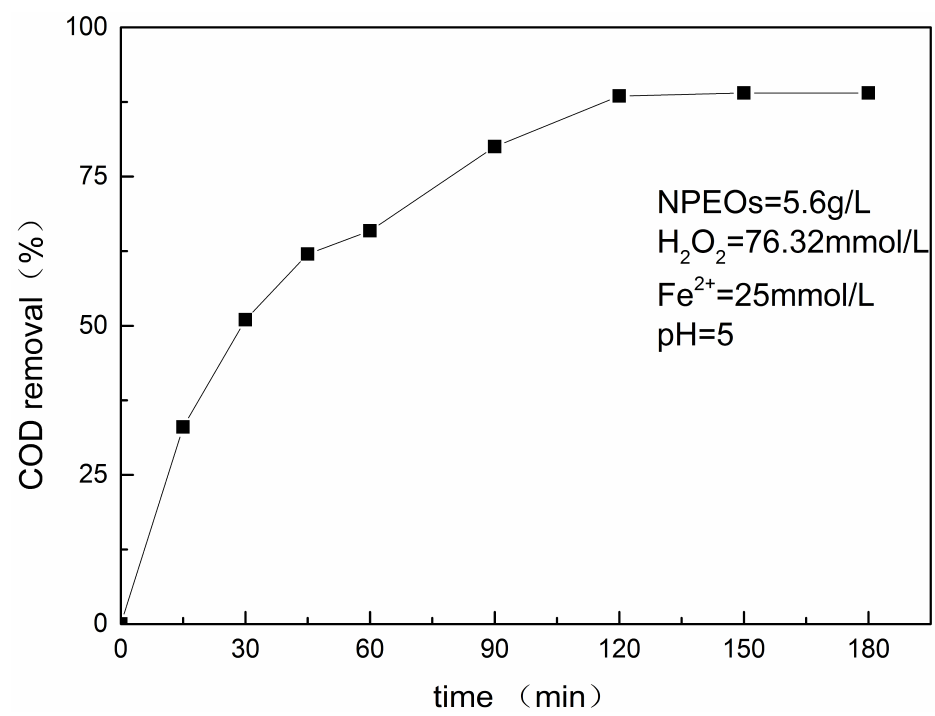

Figure 2. COD removal of the NPEOs wastewater by the Fenton process. 
[17] [18]. It was speculated that the optimal $\mathrm{pH}$ in reaction process was still in the range of $3-4$, which was coincident with the values reported in the literatures [19] [20].

\subsection{Effect of pH and Dosage on Solubility of FeS}

When FeS particle was added to acid aqueous solution, rotten eggs smell generated in a short time, and the color of the solution changed from colorless to light green in $30 \mathrm{~s}$. The effect of $\mathrm{pH}$ on solubility of FeS was shown in Figure 3. And the effect of dosage of FeS on solubility of FeS was shown in Figure 4.

As can be seen from Figure 3, only less $10 \%$ of FeS dissolved in the acid aqueous solution within $4 \mathrm{~h}$ when the $\mathrm{pH} \geq 3$. When the $\mathrm{pH}=2,23 \%$ of $\mathrm{FeS}$ dissolved and 141 $\mathrm{mg} / \mathrm{L}$ ferrous ion generated in the aqueous solution. The amount of dissolved FeS increased with the reaction time increasing whatever the $\mathrm{pH}$ was in the solution. When the $\mathrm{pH}=2$, the FeS dissolution rate is fast because of the enough $\mathrm{H}^{+}$in the solution.

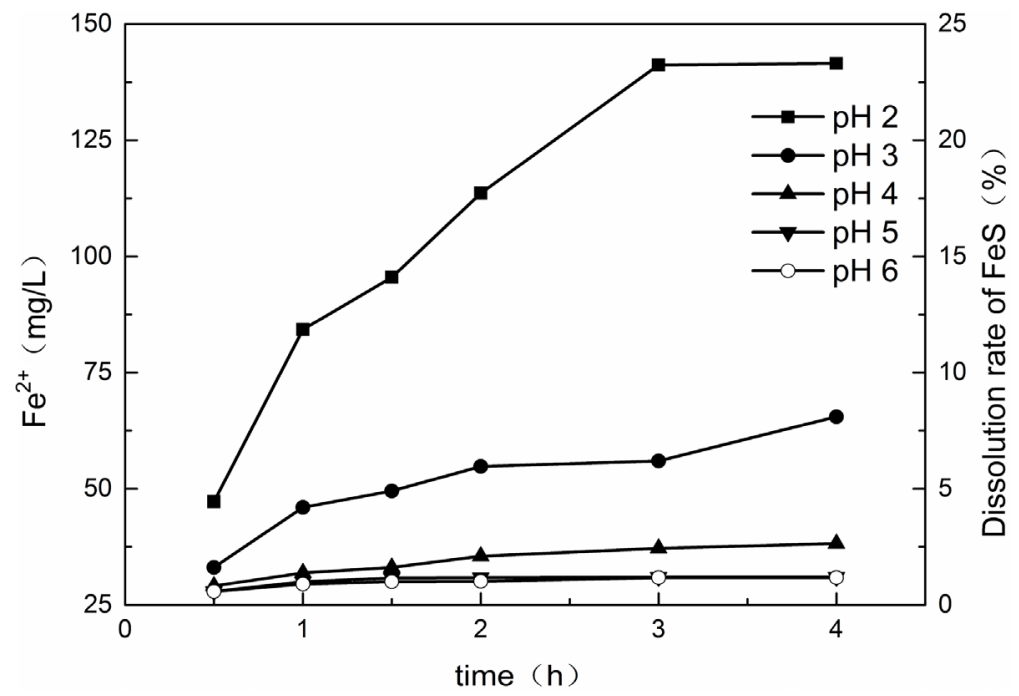

Figure 3. The effect of $\mathrm{pH}$ on solubility of FeS.

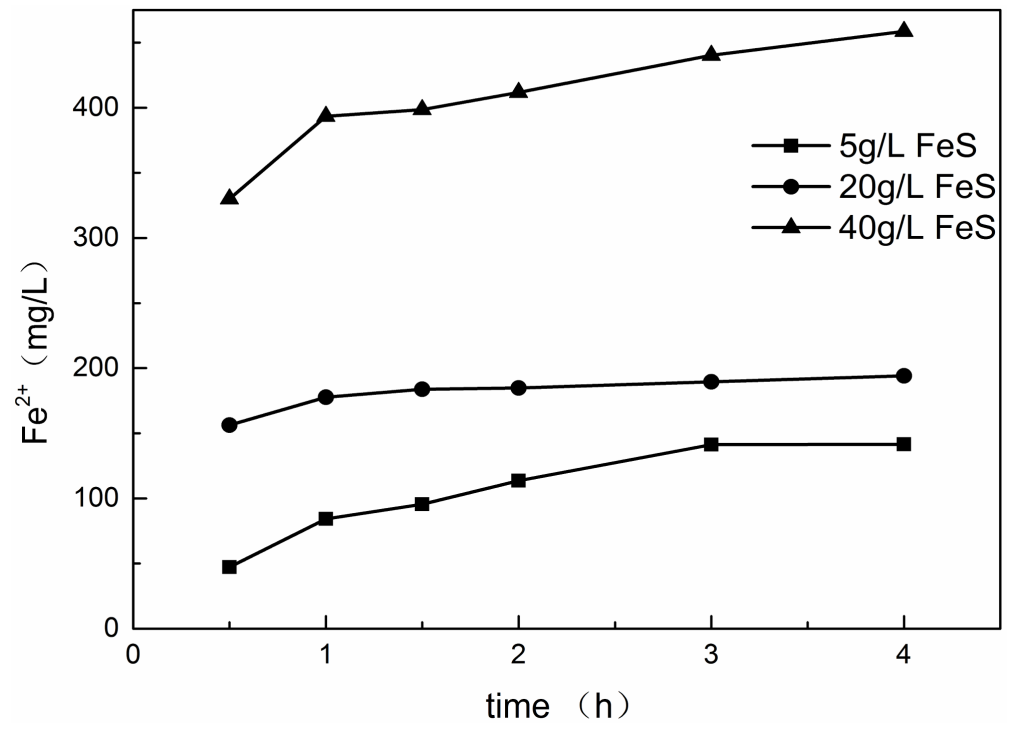

Figure 4. Effect of dosage on solubility of FeS $(\mathrm{pH}=2)$. 
And as can be seen from Figure 4, the concentration of ferrous ion kept an increasing with increase of the dosage of FeS, and $25 \%-30 \%$ of $\mathrm{FeS}$ had dissolved no matter the dosage of FeS was $5 \mathrm{~g} / \mathrm{L}, 20 \mathrm{~g} / \mathrm{L}$, or $40 \mathrm{~g} / \mathrm{L}$.

\subsection{The Iron Reusability Studies}

According to the results of solubility of FeS in the aicd solution, selected the dosage of FeS was $5 \mathrm{~g} / \mathrm{L}, 25 \mathrm{~g} / \mathrm{L}$ and $50 \mathrm{~g} / \mathrm{L}$ to reduce the iron-containing sludge, respectively. The concentration of iron ion generated in the solution and COD removal with the reduced sludge as catalyst in Fenton process were shown in Figure 5.

As can be seen from Figure 5, when the dosage of FeS is $5 \mathrm{~g} / \mathrm{L}, 25 \mathrm{~g} / \mathrm{L}$ and $50 \mathrm{~g} / \mathrm{L}$, the concentration of ferrous ion in the reaction mixture is $140.7 \mathrm{mg} / \mathrm{L}, 278.1 \mathrm{mg} / \mathrm{L}$ and $367.6 \mathrm{mg} / \mathrm{L}$, respectively. It shows that the concentration of ferrous ion still keep an increasing trend in the iron-containing sludge with a slow growth rate. This could be seen from the Equations (1)-(4), the $\mathrm{Fe}^{2+}$ from dissolution of $\mathrm{FeS}$ and the deoxidization of $\mathrm{Fe}^{3+}$ make the concentration of ferrous iron ion trend a balanced concentration in the whole mixed liquor. Besides, the concentration of ferric ion just increases slightly. It shows that the dissolution rate of FeS in the mixture solution is smaller, that is to say the Equation (1) is inhibited by the $\mathrm{Fe}^{2+}$ from the deoxidization of $\mathrm{Fe}^{3+}$-containing sludge. An interesting phenomenon is that the $\mathrm{Fe}^{2+} / \mathrm{Fe}^{3+}$ ratio become high with the increase of the dosage of FeS.

We reuse all the mixed liquor after reaction with $\mathrm{FeS}$ as catalyst for the Fenton process in NPEOs wastewater treatment, the reaction condition is same as the first Fenton process except the molar ratio of $\mathrm{H}_{2} \mathrm{O}_{2} / \mathrm{Fe}^{2+}$. And The COD removal is shown in Figure 5 (the line graph). By the calculation, the molar ratio of $\mathrm{H}_{2} \mathrm{O}_{2} / \mathrm{Fe}^{2+}$ in the second Fenton process is different from molar ratio of $\mathrm{H}_{2} \mathrm{O}_{2} / \mathrm{Fe}^{2+}$ in the first Fenton process. Even so, the COD removal efficiency is as good as the first time. It might be because of the presence of the escaping FeS fine particles and the iron-containing sludge, prompting the Fenton-like process in the whole reaction system. On the whole, all the iron-containing sludge is disposed and reused in the Fenton process.

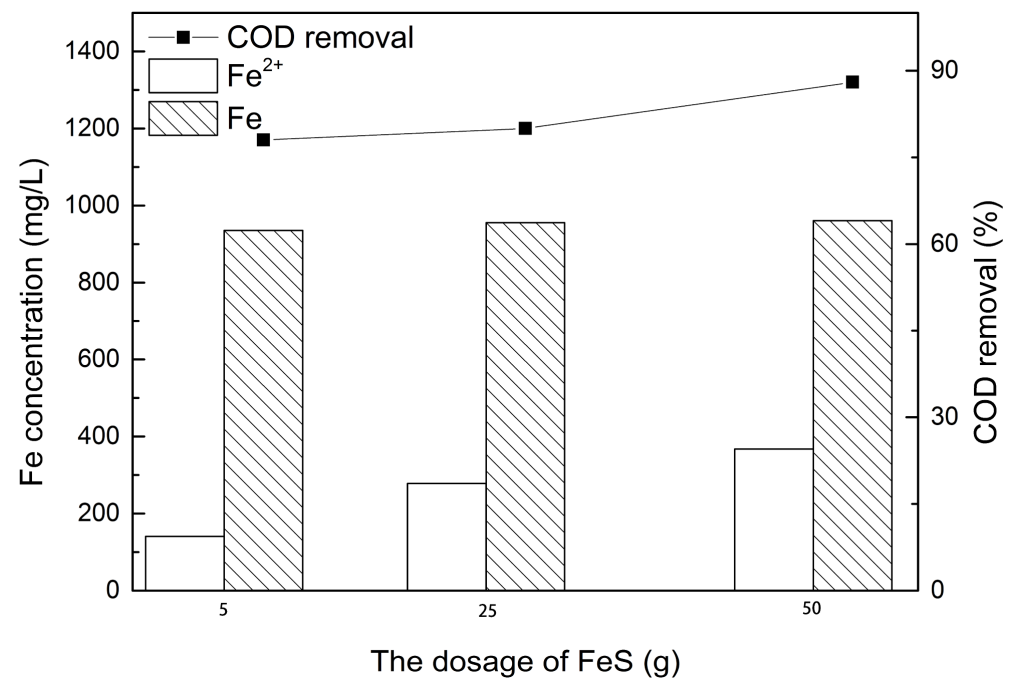

Figure 5. The studies of iron reusability and COD removal. 


\section{Conclusions}

The Fenton process was determined to be an effective technique to treat NPEOs wastewater. Under the optimum operation conditions, the COD removal was $89 \%$.

The Fenton sludge could be reduced to produce a certain amount of $\mathrm{Fe}^{2+}$ in the acidic mixed liquor by FeS and this mixed liquor could be used as the new catalyst in the Fenton process without any sludge discharge. The COD removal of the NPEOs wastewater was nearly $80 \%$. After proper regulation, the new method of reducing Fenton sludge could be used in the actual industry totally. And the reaction devices and the treatment of excess $\mathrm{H}_{2} \mathrm{~S}$ should be further explored.

\section{Acknowledgements}

This study was financially supported by Shanghai University of Engineering Science Innovation Fund for Graduate Students (No: E1-0903-15-01035).

\section{References}

[1] David, L. and Anders, W. (1991) Oxidation of Chlorobenzene with Fenton's Reagent. Environmental Science \& Technology, 25, 777-782. https://doi.org/10.1021/es00016a024

[2] Yang, D. and James, D. (2006) Treatment of Landfill Leachate by the Fenton Process. Water Research, 40, 3683-3694. https://doi.org/10.1016/j.watres.2006.08.009

[3] Jie-Chung, L., Yu-Jen, H. and Jia-Yun, H. (2009) Treatment of Printed Circuit Board Industrial Wastewater by Ferrite Process Combined with Fenton Method. Journal of Hazardous Materials, 170, 620-626. https://doi.org/10.1016/j.jhazmat.2009.05.020

[4] Bautista, P., Mohedano, A.F., Casas, J.A., Zazo, J.A. and Rodriguez, J.J. (2008) An Overview of the Application of Fenton Oxidation to Industrial Wastewaters Treatment. Journal of Chemical Technology and Biotechnology, 83, 1323-1338. https://doi.org/10.1002/jctb.1988

[5] Garrido, E., Theng, B. and Mora, M. (2010) Clays and Oxide Minerals as Catalysts and Nanocat-Alysts in Fenton-Like Reactions-A Review. Applied Clay Science, 47, 182-192. https://doi.org/10.1016/j.clay.2009.11.044

[6] Anh, L., Fiona, M. and David, L. (2012) Kinetics and Efficiency of $\mathrm{H}_{2} \mathrm{O}_{2}$ Activation by Iron-Containing Minerals and Aquifer Materials. Water Research, 46, 6454-6462. https://doi.org/10.1016/j.watres.2012.09.020

[7] Aleksic, M., Kusic, H., Koprivanac, N., Leszczynska, D. and Božic, A.L. (2010) Heterogeneous Fenton Type Processes for the Degradation of Organic Dye Pollutant in Water-The Application of Zeolite Assisted AOPs. Desalination, 257, 22-29. https://doi.org/10.1016/j.desal.2010.03.016

[8] Dulova, N., Trapido, M. and Dulov, A. (2011) Catalytic Degradation of Picric Acid by Heterogeneous Fenton-Based Processes. Environmental Technology, 32, 439-446. https://doi.org/10.1080/09593330.2010.501823

[9] Ivan, M., Sergey, K., Vera, L., Alexander, G., Jean-Paul, I. and Denis, K. (2017) Nanosized Zero-Valent Iron as Fenton-Like Reagent Forultrasonic-Assisted Leaching of Zinc from Blast Furnace Sludge. Journal of Hazardous Materials, 321, 557-565. https://doi.org/10.1016/j.jhazmat.2016.09.046

[10] Mesut, T., Cengiz, Y. and Nihal, B. (2008) Heterogeneous Photo-Fenton Oxidation of Reactive Azo Dye Solutions Using Iron Exchanged Zeolite as a Catalyst. Microporous and Mesoporous Materials, 115, 594-602. https://doi.org/10.1016/j.micromeso.2008.03.001

[11] Hui, Z., Jianguo, L., Changjin, O., et al. (2016) Reuse of Fenton Sludge as an Iron Source for $\mathrm{NiFe}_{2} \mathrm{O}_{4}$ Synthesis and Its Application in the Fenton-Based Process. Journal of Environ- 
mental Sciences, In Press.

[12] Kavitha, V. and Palanivelu, K. (2004) The Role of Ferrous Ion in Fenton and Photo-Fenton Processes for the Degradation of Phenol. Chemosphere, 55, 1235-1243. https://doi.org/10.1016/j.chemosphere.2003.12.022

[13] Juri, B., Eneliis, K., Marika, V., et al. (2014) Reuse of Ferric Sludge as an Iron Source for the Fenton-Based Process in Wastewater Treatment. Chemical Engineering Journal, 255, 8-13. https://doi.org/10.1016/j.cej.2014.06.018

[14] Ruiping, L., Zhongchao, Y., Ziliang, H., et al. (2016) Treatment of Strongly Acidic Wastewater with High Arsenic Concentrations by Ferrous Sulfide (FeS): Inhibitive Effects of S(0)Enriched Surfaces. Chemical Engineering Journal, 304, 986-992. https://doi.org/10.1016/j.cej.2016.05.109

[15] Ying, G. (2006) Fate, Behavior and Effects of Surfactants and Their Degradation Products in the Environment. Environment International, 32, 417-431. https://doi.org/10.1016/j.envint.2005.07.004

[16] Soares, A., Guieysse, B., Jefferson, B., Cartmella, E., and Lestera, J.N. (2008) Nonylphenol in the Environment: A Critical Review on Occurrence, Fate, Toxicity and Treatment in Wastewaters. Environment International, 34, 1033-1049. https://doi.org/10.1016/j.envint.2008.01.004

[17] Antonio, D., and Roberto, S. (1994) Monitoring Aromatic Surfactants and Their Biodegradation Intermediates in Raw and Treated Sewages by Solid-Phase Extraction and Liquid Chromatography. Environmental Science \& Technology, 28, 850-858.

https://doi.org/10.1021/es00054a016

[18] Montserrat, S., Maria, J., Loapez, D.A. and Damia, B. (2000) Estrogencity Determination in Sewage Treatment Plants and Surface Waters from the Catalonian Area (NE Spain). Environmental Science \& Technology, 34, 5076-5083. https://doi.org/10.1021/es991335n

[19] Karci, A., Arslan-Alaton, I., Bekbolet, M., Gul, O. and Buket, A. (2014) $\mathrm{H}_{2} \mathrm{O}_{2} / \mathrm{UV}-\mathrm{C}$ and Photo-Fenton Treatment of a Nonylphenol Polyethoxylate in Synthetic Freshwater: Follow-Up of Degradation Products, Acute Toxicity and Genotoxicity. Chemical Engineering Journal, 241, 43-51. https://doi.org/10.1016/j.cej.2013.12.022

[20] Pagano, M., Lopez, A., Volpe, A. and Ruggiero, C. (2008) Oxidation of Nonionic Surfactants by Fenton and $\mathrm{H}_{2} \mathrm{O}_{2} / \mathrm{UV}$ Processes. Environmental Technology, 29, 423-433. https://doi.org/10.1080/09593330801983862

\section{Submit or recommend next manuscript to SCIRP and we will provide best service} for you:

Accepting pre-submission inquiries through Email, Facebook, LinkedIn, Twitter, etc. A wide selection of journals (inclusive of 9 subjects, more than 200 journals)

Providing 24-hour high-quality service

User-friendly online submission system

Fair and swift peer-review system

Efficient typesetting and proofreading procedure

Display of the result of downloads and visits, as well as the number of cited articles

Maximum dissemination of your research work

Submit your manuscript at: http://papersubmission.scirp.org/

Or contact cweee@scirp.org 